\title{
Correction to: Well-Being and Stability among Low-income Families: A 10-Year Review of Research
}

\author{
Yoshie Sano $^{1}$ (1) $\cdot$ Sheila Mammen ${ }^{2} \cdot$ Myah Houghten $^{3}$
}

Published online: 28 December 2020

(c) Springer Science+Business Media, LLC, part of Springer Nature 2020

\section{Correction to: Journal of Family and Economic Issues https://doi.org/10.1007/s10834-020-09715-7}

The article "Well-Being and Stability among Low-Income Families: A 10-Year Review of Research", written by "Yoshie Sano, Sheila Mammen, Myah Houghten", was originally published online on the publisher's internet portal on 25 October 2020 with Open Access under a Creative Commons Attribution 4.0 International License.

With the author's/authors' decision to cancel Open Access the copyright of the article changed on 14 December 2020 to $@$ Springer Science+Business Media, LLC, part of Springer Nature 2020 with all rights reserved.

The original article has been corrected.

The original article can be found online at https://doi.org/10.1007/ s10834-020-09715-7.

Yoshie Sano

yoshie_sano@wsu.edu

Sheila Mammen

smammen@resecon.umass.edu

Myah Houghten

houghten@wsu.edu

1 Department of Human Development, Washington State

University Vancouver, 14204 NE Salmon Creek Avenue,

Vancouver, WA 98686, USA

2 Department of Resource Economics, University of Massachusetts Amherst, 309 Stockbridge Hall, Amherst, MA 01003, USA

3 Child and Family Research Unit, Washington State University Extension, 412 E. Spokane Falls Blvd, Spokane, WA 99202, USA
Publisher's Note Springer Nature remains neutral with regard to jurisdictional claims in published maps and institutional affiliations. 